\title{
PRIME FACTORS IN THE ETIOLOGY OF CONGENITAL DISLOCATION OF THE HIP*
}

\author{
John A. Wilkinson, London, England \\ From the Institute of Orthopaedics and the Royal National Orthopaedic Hospital, London and Stanmore \\ "The intra-uterine mechanical causes afford a tempting field for investigation." \\ Tubby 1912.
}

Environmental theories of etiology are based on the fundamental belief that the development of the hip joint, in the majority of congenital dislocations, is normal until the later stages of pregnancy, when it is influenced by exceptional intra-uterine conditions. "The primary cause is mechanically simple" (Denis Browne 1936), but there is growing evidence that physiological factors play an important role in the dislocating mechanism.

The outstanding clinical features relevant to the etiology of this malformation include its presence at birth, the sex incidence and prevalence in birth rank. In Sweden, during the past ten years almost 70 per cent of cases have been diagnosed in the neonatal period, proving that the majority are true congenital deformities developing in utero (Andrén and Rosen 1958, Palmén 1961). The high female preponderance has long been recognised, but attention has only recently been drawn to the prevalence in first-born children (Record and Edwards 1958), who it is estimated are twice as likely to be affected as successive siblings.

Genetic factors are being investigated in a clinical survey at the Hospital for Sick Children, Great Ormond Street (Carter and Wilkinson, unpublished). Although the familial incidence is only 8 per cent, bilateral acetabular dysplasia appears in 40 per cent of cases (Wilkinson and Carter 1960). A similar dysplasia is found in one or both parents, proving its genetic origin. Familial joint laxity is present in 80 per cent of male and 25 per cent of female patients. As the name implies, near relatives are also affected. Since more than half the cases do not reveal either of these genetic factors, they cannot be essential to the mechanism of dislocation; yet their presence appears to raise the susceptibility of the hip joint to dislocation in affected families.

In the above series the sex incidence and birth rank were considered to be of greater importance than the genetic factors, as 90 per cent were girls and 60 per cent first-born children. Inquiries into the history of parturition and pregnancy showed that 16 per cent were breech births and that therapeutic versions were performed in an additional 9 per cent. Therefore, evidence of persistent breech malposition existed in 25 per cent of cases. The true incidence may be much higher because the figures do not take into account the number of spontaneous versions.

Breech posture with extended knees is the only stable malposition capable of causing "prolonged forcible retention of a limb in utero" (Tubby 1912). It will be shown that the foetus commonly adopts this posture during the second trimester, but that this position does not always persist. Once the foetal spine and legs are allowed to flex, spontaneous version usually converts the breech into a cephalic presentation. In multigravidae the intra-uterine environment favours early version; low muscle tone of the uterus and excess liquor free the foetal movements, allowing flexion of the legs and spine. In primigravidae there is high uterine tone and scant liquor. This restriction of foetal movements stabilises the breech malposition by interfering with limb folding, version often being delayed up to the thirty-fourth week of pregnancy. In 10 per cent it fails to occur and the babies are born as frank breech

* The essay on which this paper is based was awarded the Robert Jones Medal and Prize of the British Orthopaedic Association in 1960. 
presentations (Vartan 1945). In a personal study of breech bi-ths in first-born infants I observed two variations of the breech malposition. The legs were usually laterally rotated, with the knees semiflexed and the feet pointing outward (Fig. 1), but occasionally the legs were medially rotated, with the knees hyperextended and the feet in equinus (Fig. 2).

Le Damany (1914) believed that the female incidence was due to anatomical sex differences in the foetal pelves, and Keith (1948) suggested that the hereditary transmission of the malformation was sex linked, conveyed by the $\mathrm{X}$ chromosome from father to daughter. The incidence is now considered to be sex limited and dependent on female endocrine production which is responsible for the development of hormonal joint laxity in the female foetus during the second and third trimesters, when oestrone and progesterone enter the foetal circulation.

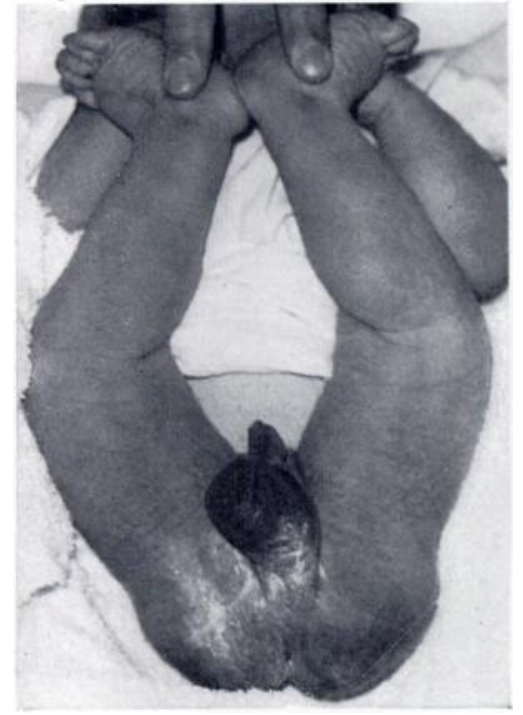

FIG. 1

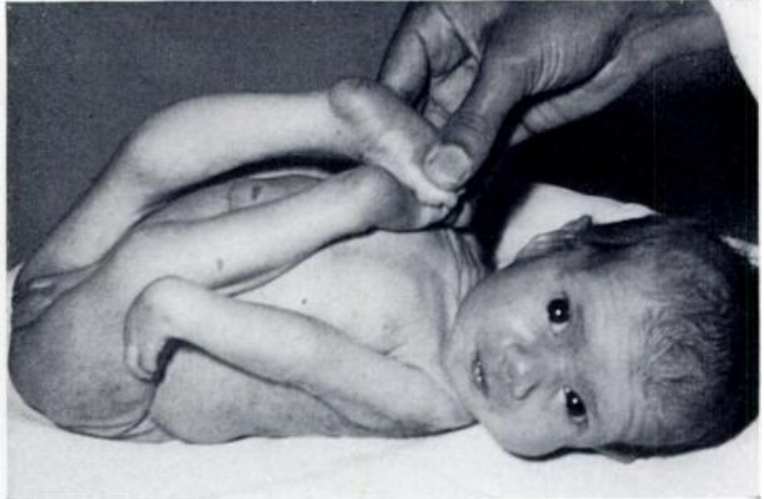

FIG. 2

Figs. 1 AND 2

Figure 1-Lateral rotation breech malposition, in the newborn. Figure 2-Medial rotation breech malposition, in the newborn.

Normally, these hormones are inactivated by the foetal liver (Andrén and Borglin 1961), but if this hepatic metabolism fails they stimulate the foetal uterus (Jost 1954) to produce relaxin (Hisaw 1926). This hormonal mechanism suggests that the foetal production of relaxin is sex limited, producing a hormonal joint laxity in the female foetus.

In quadrupeds, hormonal joint laxity affects many pregnant and immature females (Martin and Schoenbach 1959), but there is an immunity to congenital dislocation of the hips due to the relative lengths of the foetal limbs and trunk (Chapple and Davidson 1941). The short limbs and long trunk reduce the importance of limb folding as an intra-uterine space factor. There is also greater freedom of limb movements, decreasing the tendency to persistent malposition.

\section{EXPERIMENTAL INVESTIGATION}

In a series of experiments human intra-uterine factors were imposed on the hind limbs of immature female rabbits. Joint laxity was induced by injecting the respective hormones, and persistent malposition was obtained by splinting a hind limb in the breech posture. Atraumatic dislocation of the hip was produced in the splinted limbs. At necropsy, dissection of the joints revealed anatomical changes closely resembling those of human neonatal dislocations.

The results of these experiments provide valuable evidence in support of the theories of environmental etiology. They stress the importance of breech malposition and hormonal joint laxity as prime factors in the pathogenesis of congenital dislocation of the hip.

VOL. 45 B, NO. 2, MAY 1963 


\section{MATERIAL AND METHODS}

Rabbits between six and eight weeks old were chosen because their hip joints are well developed replicas of the human hip joint and because anatomy and development had been studied previously (Wilkinson 1962).

Because splintage of both hind limbs prevented the rabbits from moving about the pens only the left hind limb was immobilised in a padded plaster-of-Paris splint. The ankle was fixed at a right angle and the knee was splinted in extension. Simply by rotating the foot, torsion was applied directly to the tibia, but indirectly to the femur and hip by transmission through the taut collateral ligaments of the knee. The hip was then flexed to bring the splinted limb on to the ventral surface of the abdomen, where it was fixed in the rotated malposition by a plaster band encircling the rabbit's trunk.

The splints were changed every two weeks under intravenous nembutal anaesthesia. Radiographs of the pelvis, hip and femur were taken each week to show any change in position and the development of dislocation. After six weeks of splintage the rabbits were killed, the plasters removed and radiographs taken of the pelvis and hips. Both legs were dissected, the anatomical features were photographed and the bones were measured.

In experiments on hormonal joint laxity, male and female rabbits were sensitised by oestrone and then given progesterone (Hisaw, Zarrow, Money, Talmage and Abramowitz 1944). Excessive pelvic ligamentous laxity developed in the female rabbits, but only slight changes were detected in the male rabbits (Martin and Schoenbach 1959). Three intramuscular injections of oestrone (15 milligrams oestrone in 0.6 millilitres of 20 per cent ethyl oleate with arachis oil) were given to each animal in the first week, and thereafter they received three injections of progesterone ( 0.5 millilitres Progestin, 10 milligrams/millilitre) a week for five weeks. The plaster splints were applied after the second injection of progesterone. By this time hormonal joint laxity had developed in the females, its presence being confirmed by springing the pelvis and by the ease with which the malposition was imposed on the splinted limb. The femoral heads would not subluxate when forced backwards in these animals.

At necropsy laxity was present in the sacro-iliac joints, the symphysis pubis, the hips and the knees, but histological examination failed to show any gross changes in the capsular ligaments of these joints. The animal's sex was confirmed; in the female rabbits the uteri were hypervascular and three times the normal size.

\section{RESULTS OF EXPERIMENTS}

Lateral rotation breech malposition-This human posture (Fig. 1) was difficult to impose on the control animals without hormone injections. Part of the flexion, in bringing the splinted leg on to the abdomen, occurred in the lumbar spine, but the kyphosis gradually disappeared during the following two weeks. Serial radiographs did not show subluxation or dislocation of the hip, and the knee remained extended (Fig. 3).

In the female rabbits given hormone injections the splinting was easier than in the controls, and the same was true, but to a lesser extent, in the males with hormones. The slight lumbar kyphosis produced by flexion of the limbs disappeared within three days. Radiographs taken soon after the first splint was applied revealed only a few degrees of knee flexion. By the end of the first week further flexion had occurred, and at the end of the second week there were 90 degrees of flexion. At the same time the femur was seen to rotate laterally, the femoral head appeared to roll over the posterior acetabular rim and dislocate from it (Fig. 4). In one male rabbit these changes were delayed until the sixth week, and in the other one they failed to occur altogether.

Necropsy findings-The control rabbits provided evidence of the effects of malposition and normal joint laxity. None of the hips dislocated and there were no soft-tissue changes. Excessive degrees of retroversion developed, mostly in the distal metaphyses of the splinted femora (Fig. 5). 


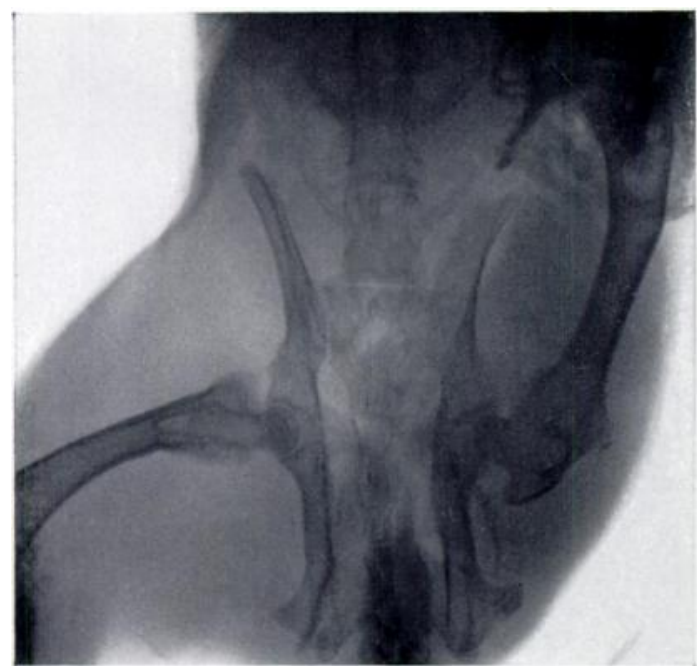

FIG. 3

Figs. 3 AND 4

Lateral rotation breech malposition. Figure 3-Radiograph of control rabbit after six weeks of splintage. There is no dislocation and the knee remains extended. Figure 4-Female rabbit which received hormones and splintage. Necropsy radiograph. The left hip has dislocated and there is subluxation of the right hip due to ligamentous laxity.

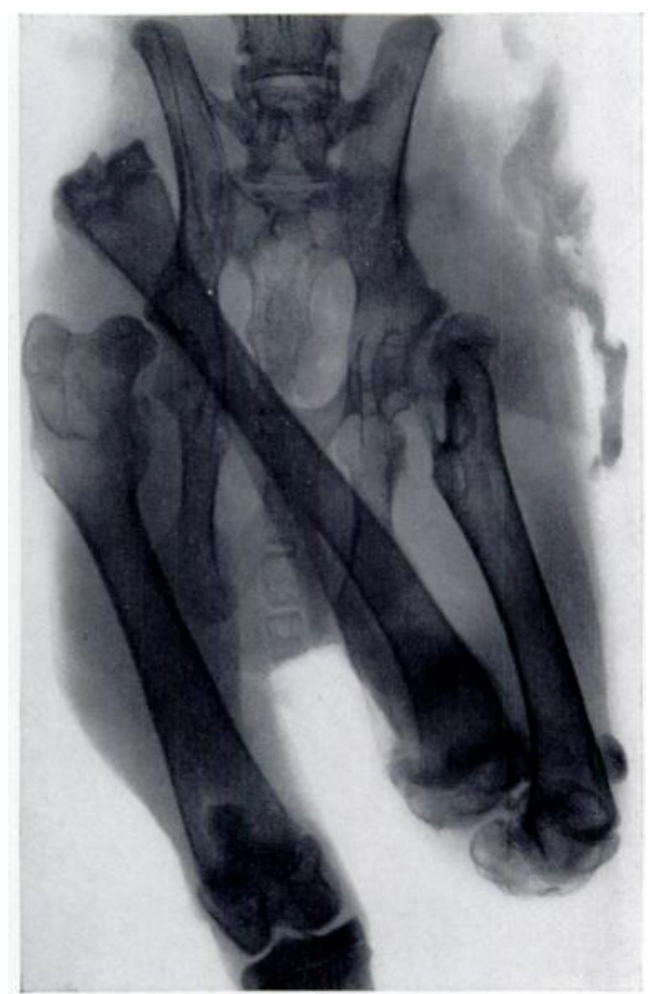

FIG. 4

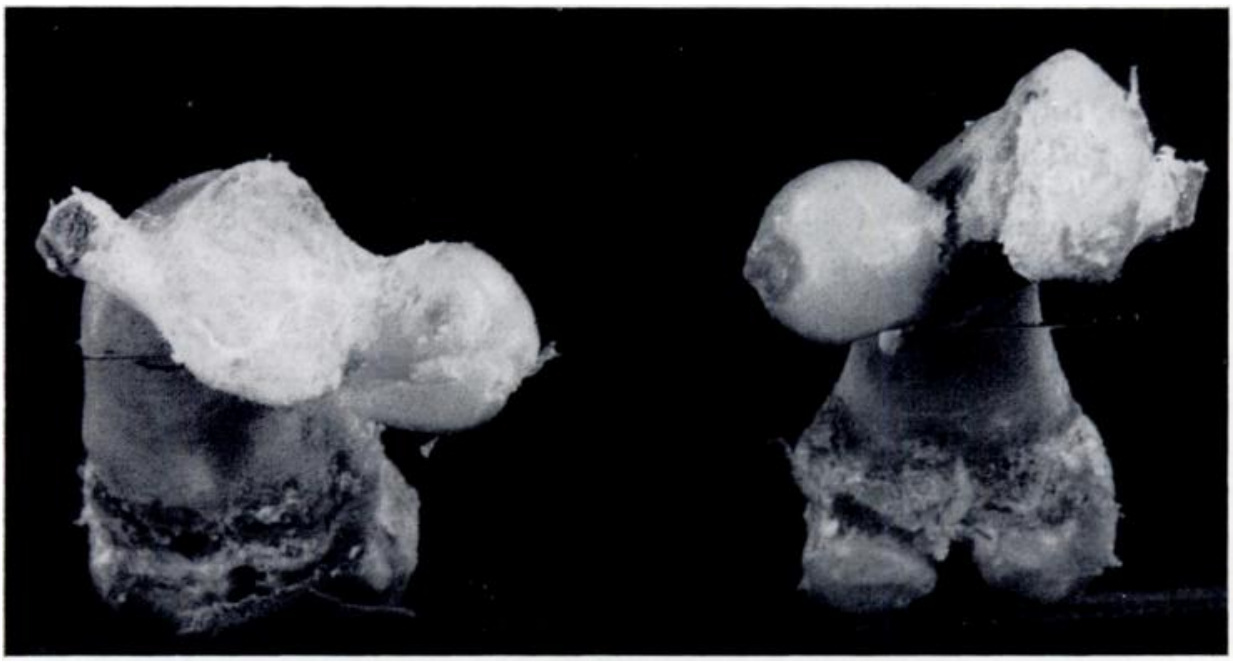

Fig. 5

Control rabbit showing femoral retroversion. Most of the deformity is confined to the distal metaphysis. 


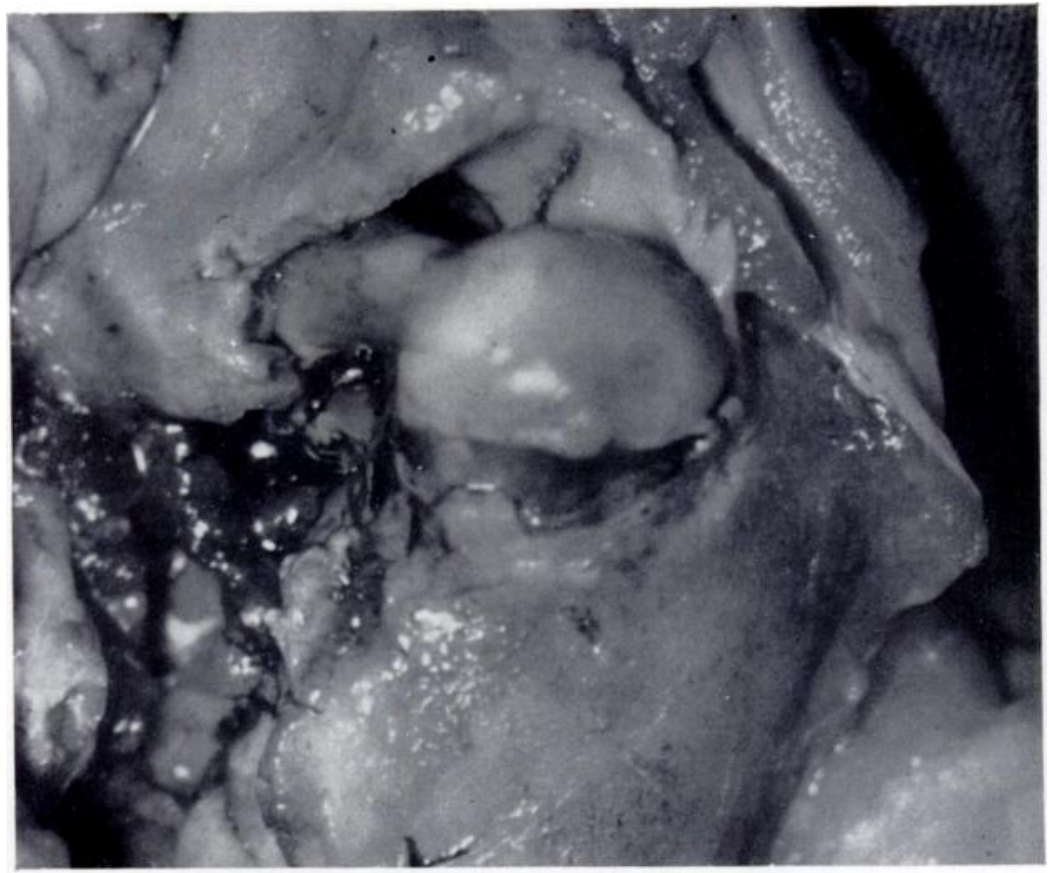

FIG. 6

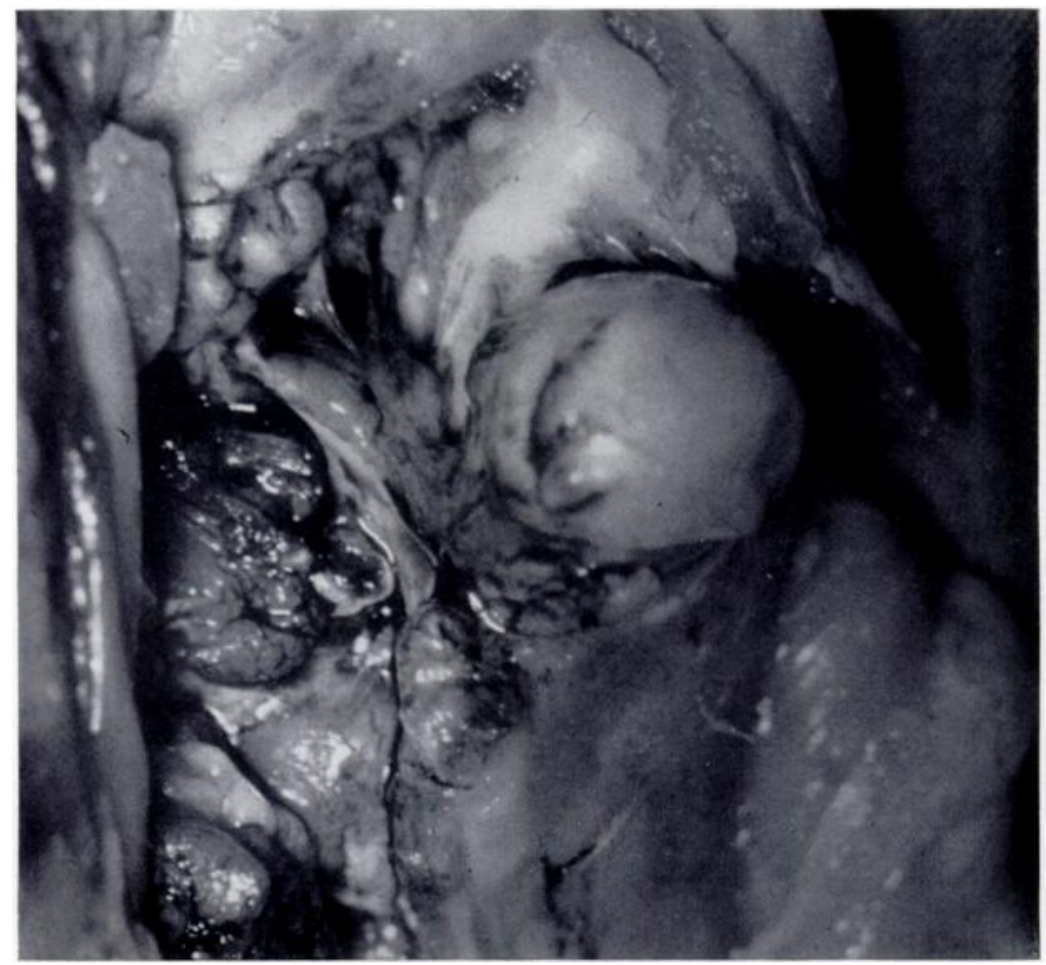

Fig. 7

Lateral rotation breech malposition. Figure 6-Necropsy dissection of the same rabbit as in Figure 4 showing a hypertrophied ligamentum teres. Posteriorly there is a white limbus lying between the femoral head and acetabulum. Figure 7Appearance of limbus following division of ligamentum teres. 


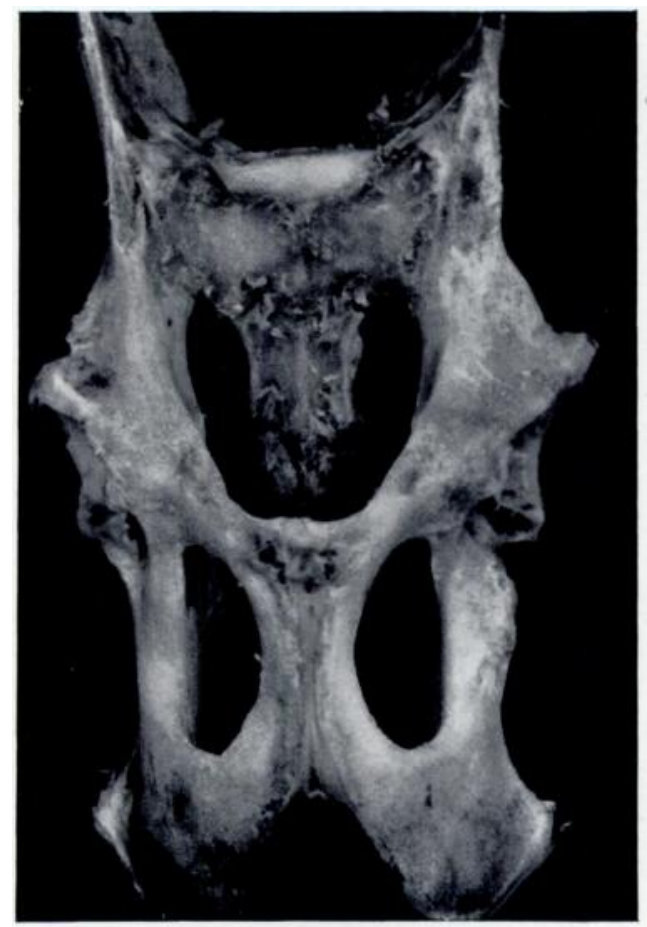

Fig. 8

The dried pelvis of the same rabbit. The left hip shows a posterior defect but no anterior dysplasia. The right hip shows a sloping roof secondary to joint laxity.

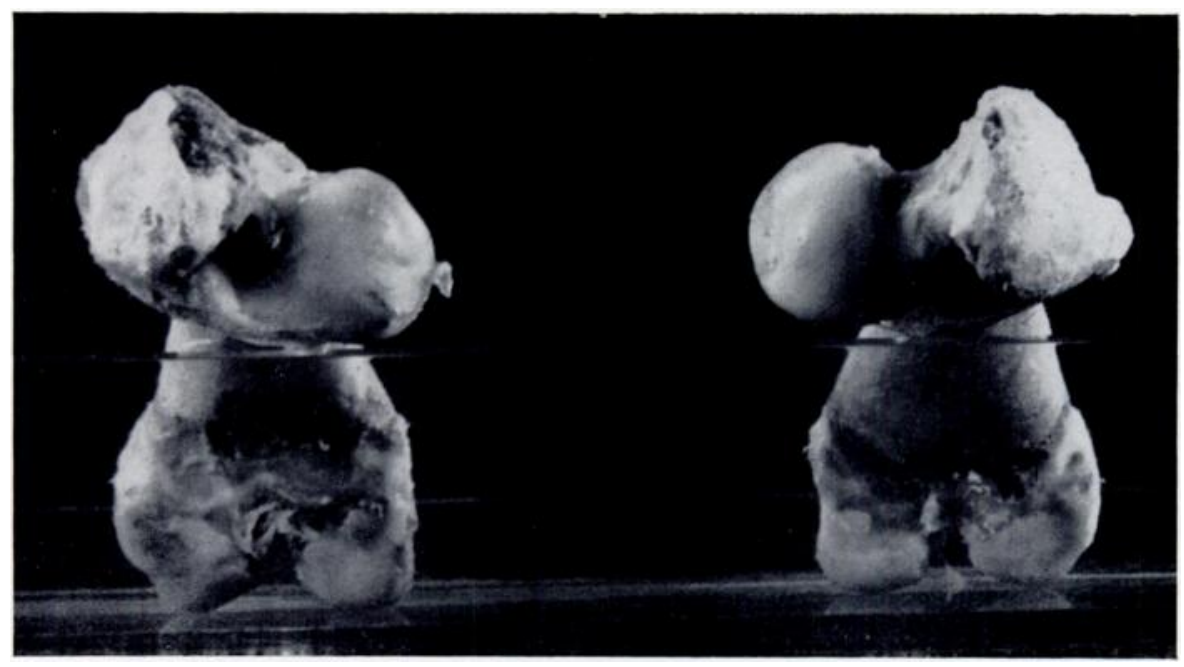

Fig. 9

The dried femora of the same rabbit. The left has a smaller head than the right and it is retroverted. Most of the deformity is confined to the proximal metaphysis. 
In the female rabbits, which had received hormones, the splinted limbs revealed the effects of malposition in the presence of increased joint laxity. Knee flexion and lateral rotation of the thigh were associated with posterior dislocation of the hip. The anterior capsule was thinly stretched between the acetabular rim and the femoral neck. The intraarticular changes were found to be slight and there was no evidence of traumatic dislocation. The ligamentum teres was lengthened and hypertrophied (Fig. 6), and when divided a thick white limbus was seen to lie close to the posterior acetabular rim (Fig. 7), separating the dislocated femoral head from the acetabulum. This impeded any attempt at reduction of the dislocation which carried the limbus into the joint, to lie between the femoral head and the roof of the acetabulum. The posterior part of the acetabular rim was notched and the attached labrum appeared atrophic (Fig. 17). Examination of the dried bones revealed a defect in the posterior acetabular rim (Fig. 8). The femur was retroverted at its proximal metaphysis and the head was smaller than normal (Fig. 9). There were no capsular changes in the free hips, but the dried bones showed slight acetabular dysplasia, secondary to the ligamentous laxity. The femora appeared normal.

In the male rabbits which had received hormones normal joint laxity was present, and the structure of the free hind limbs was normal. In the male rabbit in which the splinted hip had not dislocated no changes were present. In the one with late dislocation the posterior capsule was inverted but it was not adherent or thickened (Fig. 16). Both the splinted femora were retroverted more than those of the female rabbits which had received hormones, but less than in the control animals.

The results of the lateral rotation breech malposition experiments are shown in Table I.

TABLE I

Lateral Rotation Breech Malposition

\begin{tabular}{|c|c|c|c|c|}
\hline Sex & Hormones & $\begin{array}{c}\text { Ligament } \\
\text { laxity }\end{array}$ & $\begin{array}{l}\text { Effect on } \\
\text { the hip }\end{array}$ & $\begin{array}{l}\text { Effect on } \\
\text { the femur }\end{array}$ \\
\hline $\mathrm{F}$ & Given & Marked & Dislocated & Retroverted 15 degrees \\
\hline $\mathrm{F}$ & Given & Marked & Dislocated & Retroverted 10 degrees \\
\hline$F$ & Given & Marked & Dislocated & Retroverted 10 degrees \\
\hline$F$ & Given & Marked & Dislocated & Retroverted 10 degrees \\
\hline M & Given & Slight & Late dislocation & Retroverted 20 degrees \\
\hline$M$ & Given & Slight & Not dislocated & Retroverted 20 degrees \\
\hline $\mathrm{F}$ & Not given & Nil & Not dislocated & Retroverted 20 degrees \\
\hline$M$ & Not given & Nil & Not dislocated & Retroverted 25 degrees \\
\hline $\mathrm{F}$ & Not given & Nil & Not dislocated & Retroverted 25 degrees \\
\hline
\end{tabular}

Medial rotation breech malposition-It was more difficult to flex and medially rotate the splinted hind limbs than it was to produce malposition in the lateral rotation experiments. In the control group the first radiographs revealed dislocation of the splinted hips (Fig. 10) and a severe degree of secondary dysplasia later developed. The imposition of this breech posture was easier in the rabbits which had received hormones, little force being needed in the females. Radiographically, medial rotation of the foot appeared to produce extension of the knee which then became hyperextended in the females during the period of splintage. Serial radiographs did not reveal early dislocation of the hip. In two females the hips remained 


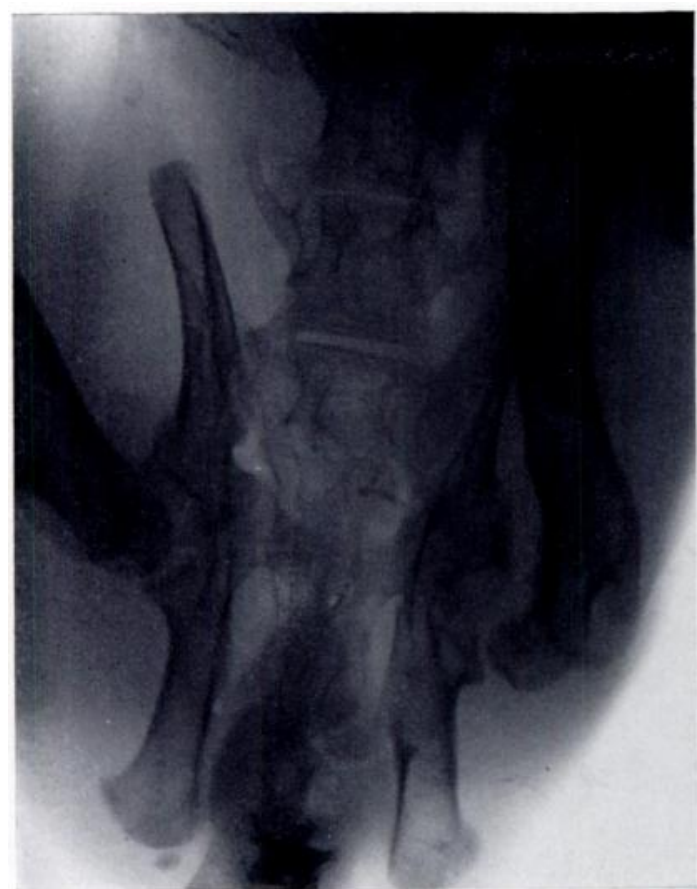

FIG. 10

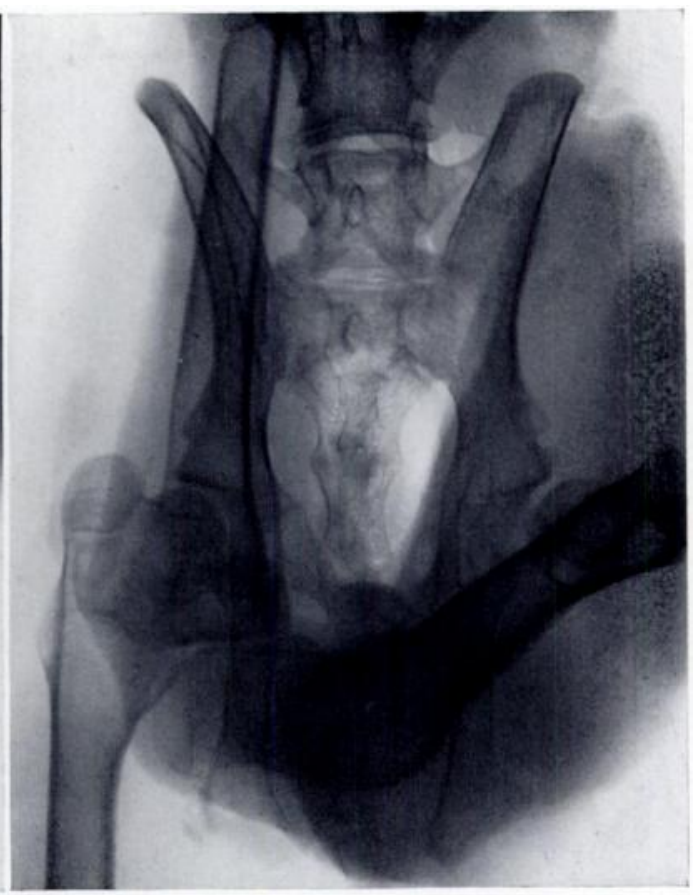

FIG. 11

Medial rotation breech malposition. Figure 10-First radiograph of control rabbit showing dislocation, later found to be traumatic at necropsy. Figure 11-Necropsy radiograph of female rabbit which had received hormones, showing severe hyperextension of the knee which resulted in atraumatic posterior dislocations of hip and knee.

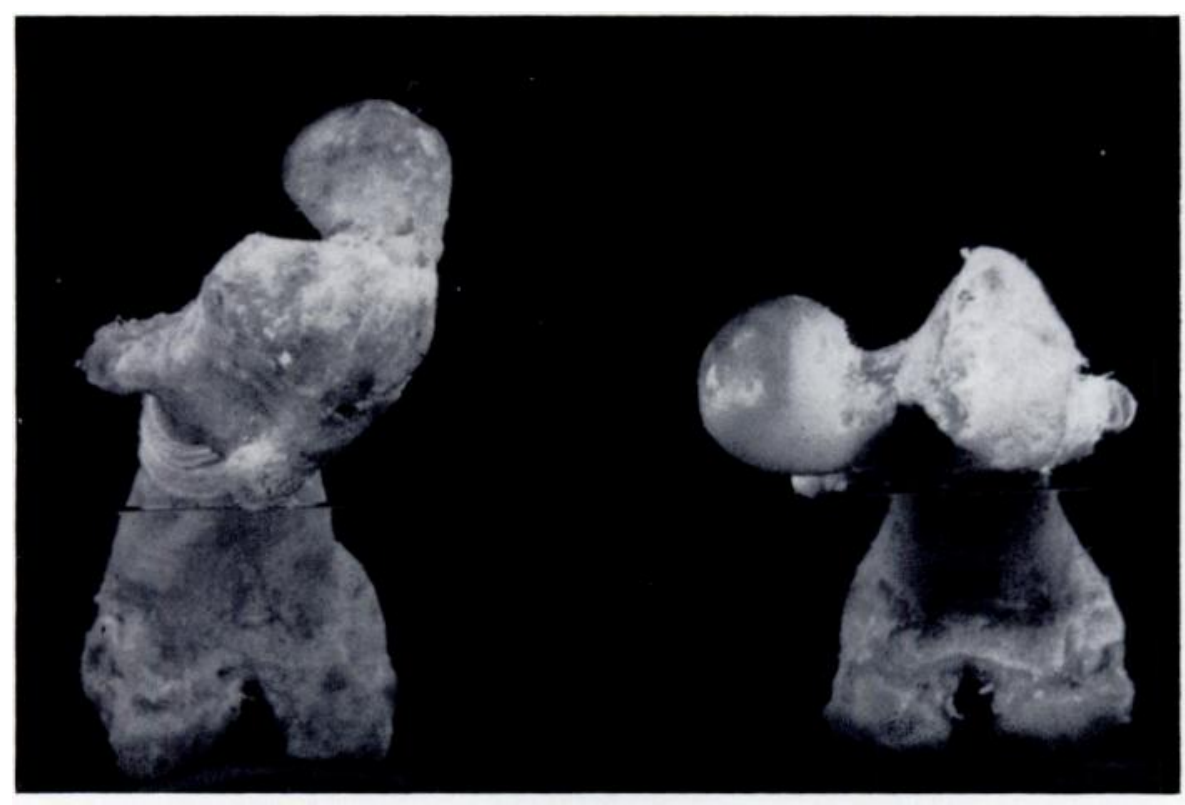

Fig. 12

Dried femora of control rabbit in Figure 10 showing femoral anteversion. Most of the deformity is confined to the distal metaphysis.

VOL. 45 B, NO. 2, MAY 1963

C 


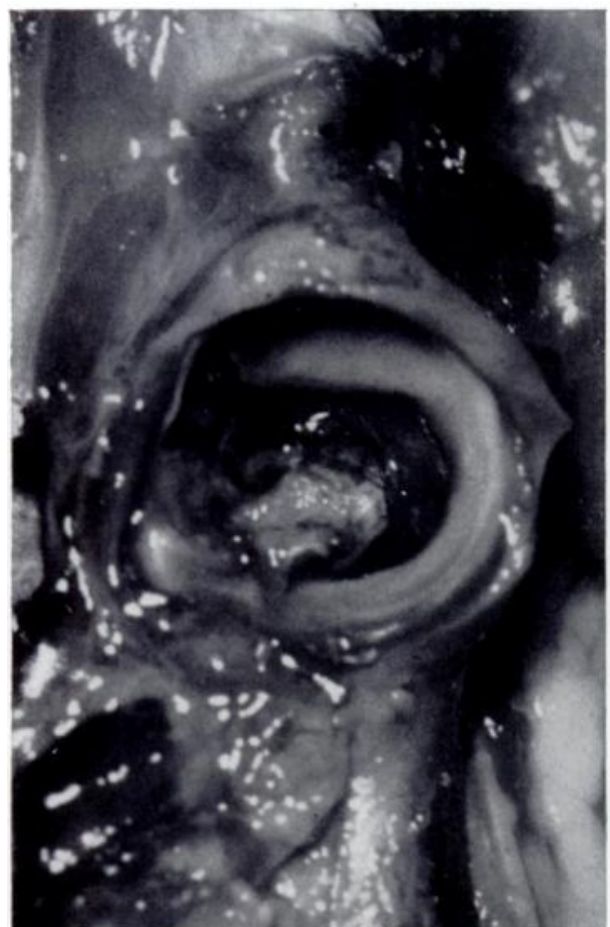

FIG. 13

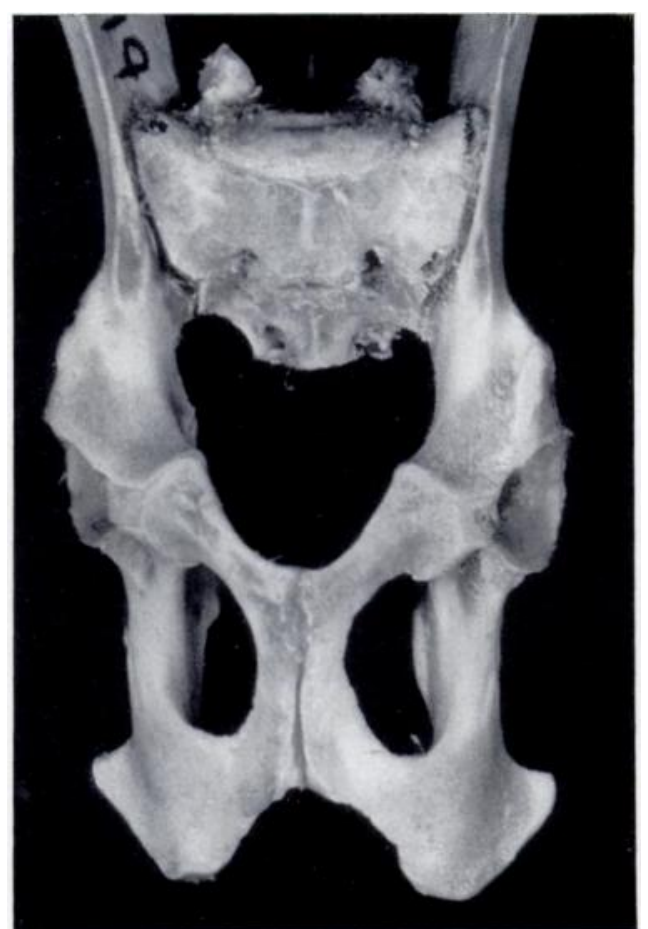

FIG. 14

Medial rotation breech malposition. Figure 13-Left acetabulum of a female rabbit which had received hormones showing anterior dysplasia. The articular cartilage has disappeared from the anterior acetabular rim. Figure 14-The pelvis of the same rabbit showing left anterior acetabular dysplasia with increased frontal inclination.

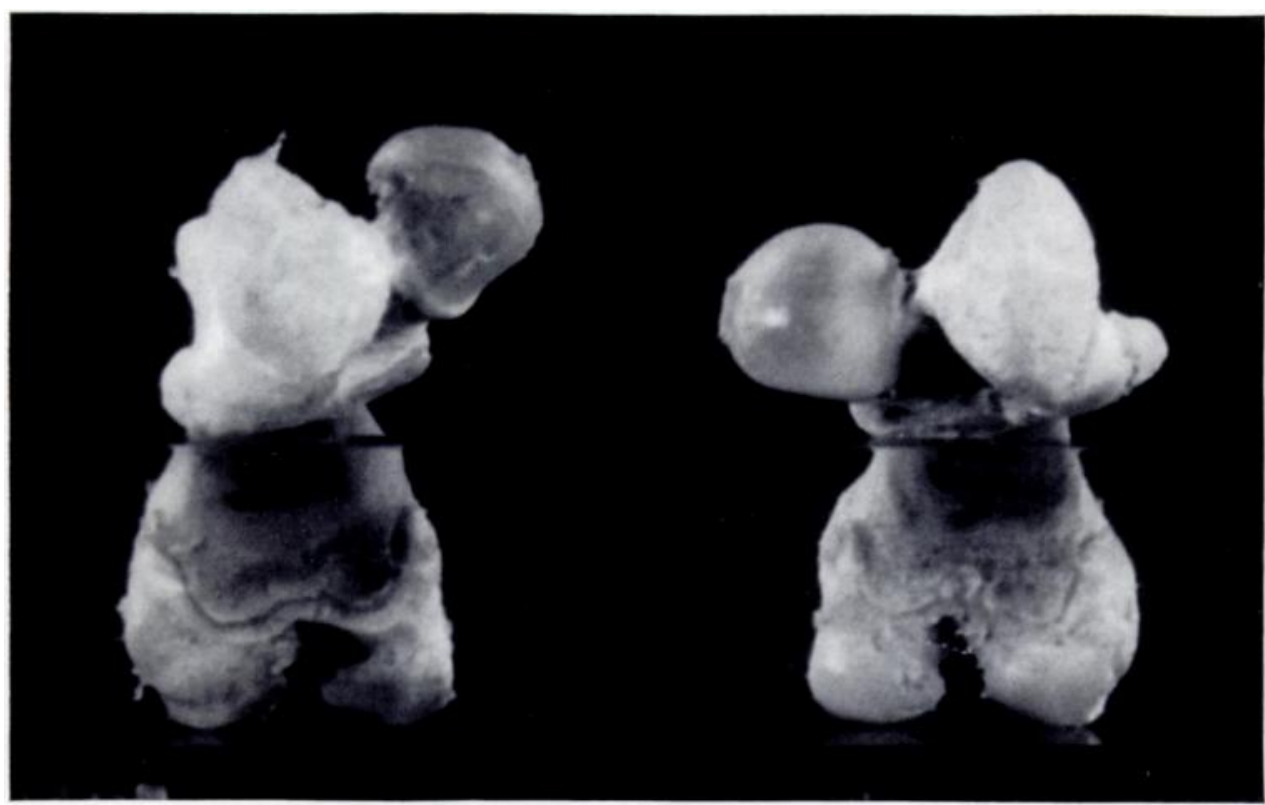

FIG. 15

The femora of the same rabbit. The left is anteverted, most of the deformity being confined to the proximal metaphysis. 
stable, but in the third the knee hyperextended by 90 degrees and later the hip dislocated posteriorly (Fig. 11). In one male rabbit the hip remained stable, but in the other one it dislocated during the last week of splintage.

Necropsy findings - In the control rabbits the malposition produced gross changes characteristic of traumatic dislocation. The distorted hip joints contained bloodstained synovial fluid and numerous adhesions; the ligamenta teres were ruptured but capsular changes were not seen. The dried acetabula on the splinted sides were shallow and deformed. Severe degrees of femoral anteversion developed in the distal metaphyses of the femora (Fig. 12).

In two of the female rabbits which had received hormones the hips had not dislocated and there were no capsular changes. The ligamenta teres appeared attenuated and twisted. The anterior rims of the acetabula were shallow and at these situations the articular cartilage had disappeared (Fig. 13). The dried bones showed anterior dysplasia, associated with frontal inclination of the acetabula (Fig. 14). The splinted femora were anteverted, but most of the deformity was confined to the proximal metaphyses (Fig. 15).

In the rabbit with the dislocated knee and hip the anterior and posterior capsules were thin but not inverted. Medial rotation of the femur had caused the femoral head to roll over the inferior acetabular rim, carrying the posterior capsule before it. The ligamentum teres was thin and attenuated. Hyperextension of the knee had caused posterior subluxation of the femoral condyles on the tibial condyles. Anterior acetabular dysplasia was present in the dried pelvis; the proximal end of the femur was anteverted and the distal metaphysis angulated posteriorly.

TABLE II

Medial Rotation Breech Malposition

\begin{tabular}{|c|c|c|c|c|}
\hline Sex & Hormones & $\begin{array}{c}\text { Ligament } \\
\text { laxity }\end{array}$ & $\begin{array}{l}\text { Effect on } \\
\text { the hip }\end{array}$ & $\begin{array}{l}\text { Effect on } \\
\text { the femur }\end{array}$ \\
\hline $\mathrm{F}$ & Given & Marked & $\begin{array}{l}\text { Dislocated } \\
\text { (also knee) }\end{array}$ & $\begin{array}{l}\text { Posterior angulation. } \\
\text { Anteverted } 20 \text { degrees }\end{array}$ \\
\hline F & Given & Marked & Not dislocated & Anteverted 30 degrees \\
\hline$F$ & Given & Marked & Not dislocated & Anteverted 20 degrees \\
\hline F & Given & Marked & Not dislocated & Supracondylar fracture \\
\hline $\mathbf{M}$ & Given & Slight & $\begin{array}{c}\text { Fracture } \\
\text { neck of femur }\end{array}$ & Anteverted \\
\hline $\mathbf{M}$ & Given & Slight & Late dislocation & Anteverted 45 degrees \\
\hline $\mathbf{M}$ & Not given & Nil & $\begin{array}{c}\text { Fracture } \\
\text { femoral shaft }\end{array}$ & Anteverted 90 degrees \\
\hline $\mathbf{F}$ & Not given & Nil & Dislocated & Anteverted 80 degrees \\
\hline $\mathbf{M}$ & Not given & $\mathrm{Nil}$ & Dislocated & Anteverted 85 degrees \\
\hline $\mathrm{F}$ & Not given & Nil & Dislocated & Anteverted 85 degrees \\
\hline
\end{tabular}

In one of the two male rabbits which had received hormones there was posterior dislocation of the hip, but no capsular change. In the other the femoral head had remained in the acetabulum, but a transcervical fracture had occurred. Examination of the dried bones showed marked degrees of anterior acetabular dysplasia on the splinted sides. Femoral anteversion was greater than in the females but less than in the control rabbits, and had developed in the proximal and distal metaphyses.

The results of the medial rotation breech malposition experiments are shown in Table II. 


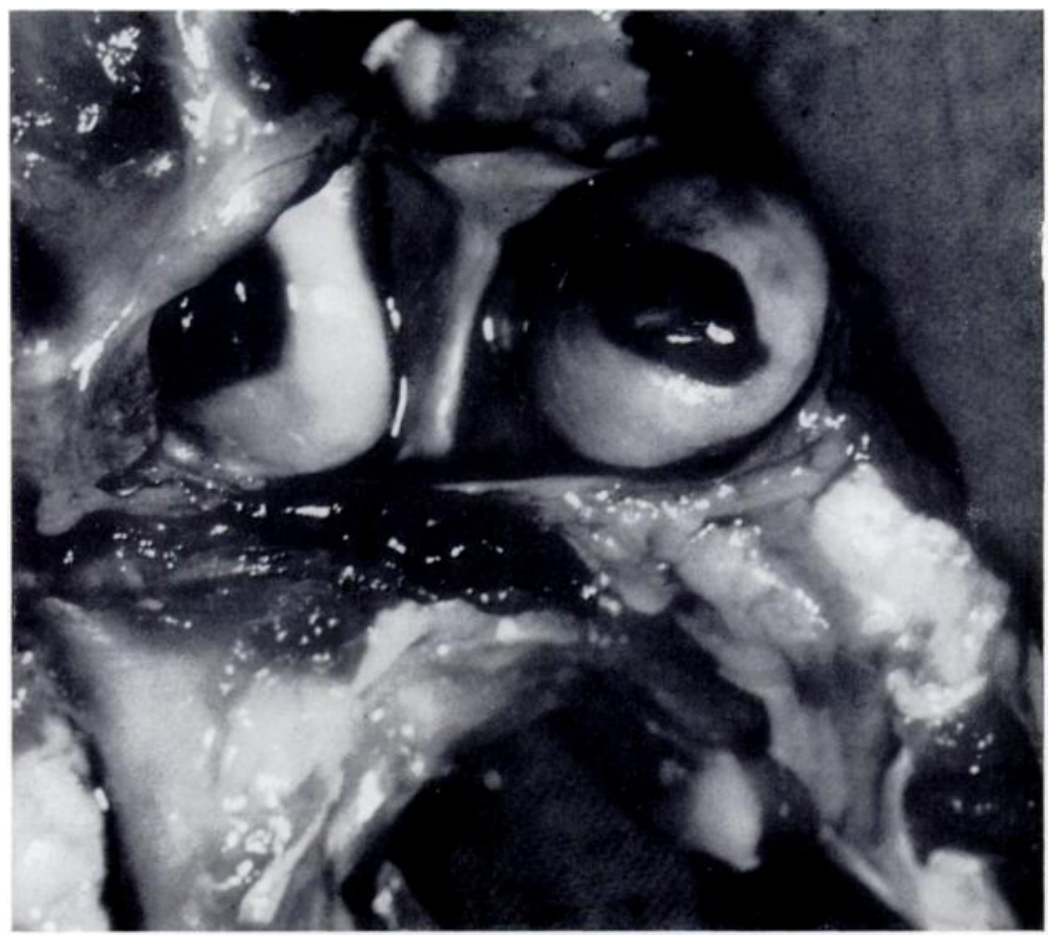

FIG. 16

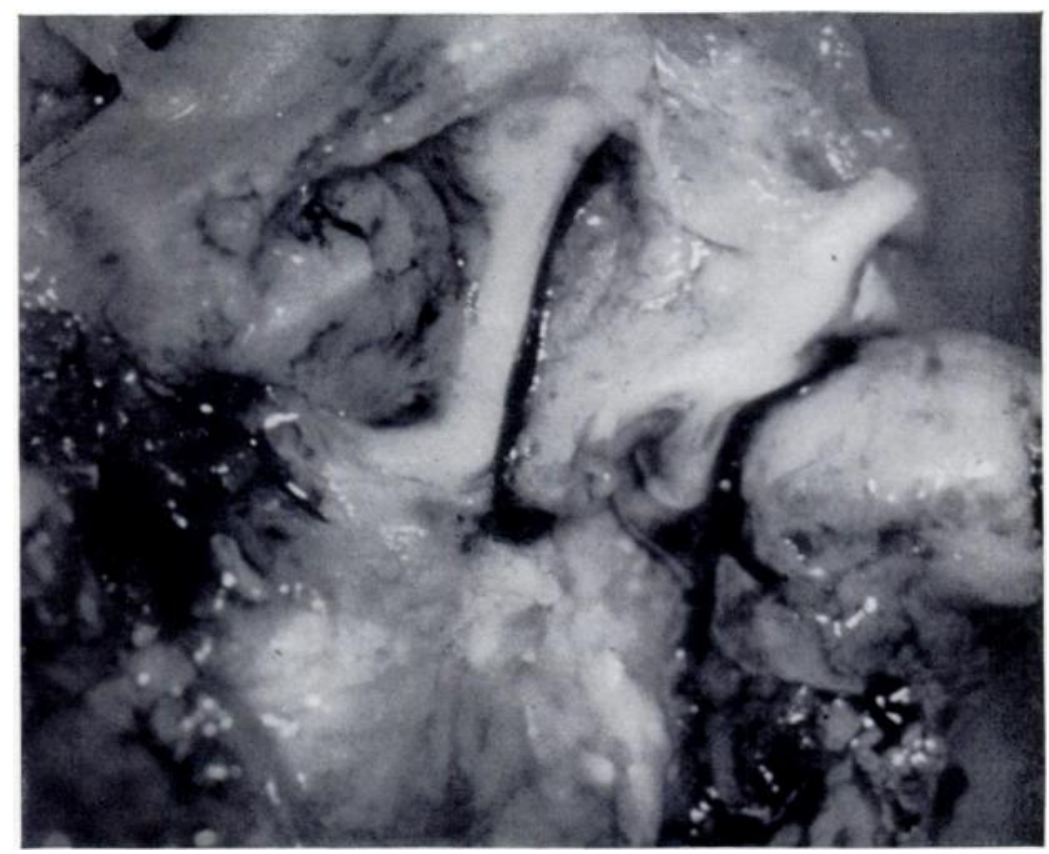

FIG. 17

Limbus formation, in lateral rotation breech malposition. Figure 16-Anterior aspect of posterior capsule showing oblique fold; from male given hormones resulting in late dislocation. Figure 17-A thickened fold divides the medial retroacetabular portion from the lateral false acetabulum which contains the femoral head; from the same rabbit as in Figures 4 to 9. 


\section{INTERPRETATION OF EXPERIMENTS}

The most significant experiments in this series are those in which the lateral rotation breech malposition was imposed in the presence of hormonal joint laxity. Soft-tissue changes and bone deformities developed in the affected hip joints, making them appear as replicas of human congenital dislocations. It is necessary to discuss their production before studying the prime etiological factors.

Soft-tissue changes-Lateral femoral rotation was responsible for the inversion of the posterior capsule of the hip, which formed an oblique fold on the inner aspect of the joint (Fig. 16). Oedema and fibrosis produced thickening of the fold and adherence of its adjacent sides (Fig. 17).

These capsular changes demonstrate the formation and structure of the limbus. It divides the posterior capsule into two parts, the medial being a retro-acetabular area and the lateral forming the roof of the false acetabulum which contains the dislocated femoral head. Similar findings were described in the posterior capsule of congenital dislocations by Fairbank (1930). The apparent close relationship of the limbus to the posterior acetabular rim has given rise to the belief that it is a hypertrophied and inverted labrum (Faber 1937). In an anatomical study of human neonatal dislocations Ortolani (1948) usually found the labrum to be squashed and atrophic, as indeed it appeared in the experiments.

The ligamentum teres never ruptured. In the presence of joint laxity, displacement of the laterally rotated femoral head over the posterior rim appeared to elongate and thicken this ligament. These changes are the result of repeated gentle stretchings, produced by recurrent atraumatic subluxations. Similar features have been reported in human congenital dislocations (Platt 1956).

Bone deformities-In the control experiments 60 per cent of femoral anteversion and retroversion developed in the distal metaphyses. The distribution of deformity is influenced by the relative rates of growth in the femoral epiphyses (Wilkinson 1962), and also depends on the sites of attachment of the capsular ligaments in relation to the epiphyses (Fig. 18).

In the female hormonal experiments the transmission of torsion from tibia to femur was affected by laxity of the capsular ligaments. This accounts for the absence of deformity in the distal metaphysis. The exaggerated anteversion, or retroversion, in the proximal metaphysis was produced by unequal growth in the anterior and posterior halves of the capital epiphysis.

Arkin and Katz (1956) analysed the effects of pressure, parallel to the direction of growth, on an epiphysis. They found that increased pressure inhibited growth, whereas decreased pressure stimulated growth. Experimentally, large forces were needed to arrest epiphysial growth, but Appleton (1934) had previously demonstrated the production of postural deformities, produced in growing animals by relatively small and intermittent forces. These hindered growth, whereas absence of normal weight-bearing stresses resulted in overgrowth.

In the breech experiments hormonal laxity allowed an increased range of rotation in the hip. Medial rotation compressed the anterior femoral head against the anterior acetabular rim (Fig. 19), but relieved compression on the posterior aspect. This retarded growth in the anterior half of the capital epiphysis and triradiate cartilage, but stimulated it posteriorly. The result was cervical anteversion and anterior acetabular dysplasia. Lateral rotation produced femoral retroversion and posterior acetabular dysplasia, by the opposite mechanism.

\section{DISCUSSION}

These experiments assess the combined effect of hormonal joint laxity and breech malposition on the hips of immature female rabbits. When acting separately neither factor dislocated the joint. Dislocation did not occur in lateral rotation breech malposition in the 
control rabbits nor did it occur as a result of hormonal joint laxity in the free hind limbs of the female rabbits which had been given oestrogen and progesterone. Therefore each factor is essential to the posterior dislocating mechanism.

Before one can assess how relevant these factors are in the etiology of human congenital dislocations their co-existence in utero must be confirmed. A review of the literature has provided a new concept of hormonal joint laxity and breech malpositions.

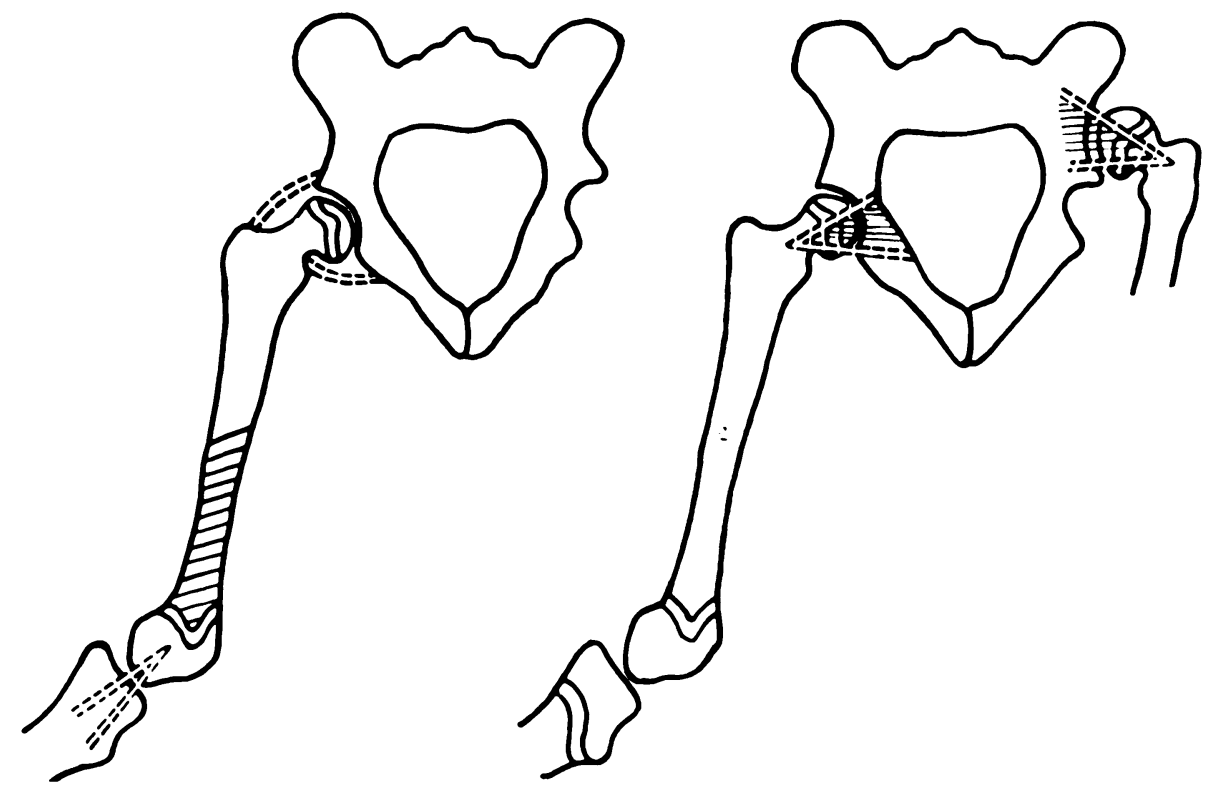

Fig. 18

FIG. 19

Femoral anteversion. Figure 18-The development of distal anteversion, with normal ligaments. Medial rotation of the tibia is transmitted by the collateral ligaments to the distal femoral epiphysis. The shaded area indicates the site of deformity. The capital epiphysis is protected from torsion by the capsular ligament of the hip and the tendon of the iliopsoas muscle. Figure 19-The development of proximal anteversion, in the presence of hormonal joint laxity. Excessive medial rotation produces compression of the anterior aspects of the capital epiphysis and the acetabulum. The shaded areas indicate the sites of compression and deformity. Rotation of the tibia is not forcibly transmitted to the distal femoral epiphysis because of the laxity affecting the collateral ligaments.

The left side demonstrates a similar mechanism in the development of post-natal anteversion of the dislocated femur.

Hormonal joint laxity - Progressive softening and lengthening of the maternal pelvic ligaments during pregnancy produces a pliancy of the birth canal and facilitates labour. Hisaw first demonstrated that these changes were under endocrine control, and later isolated relaxin as the responsible hormone. It is produced by the oestrogen-sensitised uterus as a normal response to progesterone (Hisaw et al. 1944).

Martin and Schoenbach (1959) isolated relaxin from aqueous luteal extracts and proved it to be a protein of low molecular weight. The same hormone was found in the maternal blood serum of rabbits, guinea-pigs, sows and women. The hormonal effects were demonstrated in the pubic symphyses and sacro-iliac joints of guinea-pigs and rabbits, the present experiments being the first to demonstrate laxity in the knees and hips. Hormonal laxity was not confined to the pregnant animals. Immature females developed similar changes in response to oestrone and progesterone injections. Male animals and hysterectomised females were unaffected.

The hormonal " milieu interieur" of the human foetus is the balance between the supply and metabolism of maternal, placental and foetal sources. Another controlling factor is the placento-amniotic barrier between the maternal and foetal circulations. Many maternal hormones, especially proteins, are prevented from reaching the foetus. The passage for foetal 
hormones into the maternal circulation, where many are metabolised and excreted is more free. Placental hormones have free access to the foetal circulation because they are produced in the foetal trophoblast (Jost 1954).

In the first trimester the maternal ovaries are the only source of oestrogens and progesterone, but the chorion prevents them and also relaxin from entering the foetal circulation (Diczfalusy, Cassmer, Alonso and Miquel 1961). During the second trimester, however, placental oestrone and progesterone pass into the foetal circulation. Normally, active oestrone and oestradiol-17B are conjugated by the foetal liver to form inactive oestriol, and active progesterone is also converted to inactive pregnandiol (Andrén and Borglin 1961). Oestriol and pregnandiol enter the maternal circulation and are excreted. During the third trimester the placental trophoblast degenerates, but then the foetal adrenal glands produce progesterone (Forbes 1955) and the foetal ovaries secrete oestrone (Pinkerton 1959) until the end of pregnancy, when the gonadotrophins are withdrawn.

Thus, active oestrones and progesterone are fleetingly present in the foetal serum during the second and third trimesters. They produce minor degrees of laxity by their direct action on the foetal ligaments. In the female foetus they stimulate the immature uterus to produce relaxin. This hormone has a more relaxing effect on the foetal ligaments and is responsible for the greater degrees of laxity in the females. The sex difference would be more apparent if the foetal blood levels of active oestrone and progesterone were not controlled. The foetal liver conjugates these active hormones, converting them into their inactive forms. Recently Andrén and Borglin (1961) claimed to have discovered a failure of this hepatic function in children with congenital dislocation of the hip, causing increased hormonal laxity.

Breech malposition-This is not synonymous with breech presentation. The latter merely indicates the lie of the foetus in utero, whereas the former describes a foetal posture in which the hips are flexed and the knees extended.

A great mystery of intra-uterine life is the tendency to cephalic presentation of the foetus. It has been suggested that the pyriform uterine cavity favours breech presentation during the first half of pregnancy, but gravity later exerts its influence on the heavier cephalic pole and initiates version. When the circumference of the head becomes greater than the breech then the head is accommodated more easily in the pelvis. These theories are not proven and the cause of cephalic presentation remains a mystery (Vartan 1945).

When organogenesis nears completion at the end of the second month of development (Keith 1948) the legs of the foetus project laterally with the great toe in the pre-axial position. During the third month postural changes affect the limbs. Weiss (1939) discovered that early foetal limb movements were due to the functional development of integrated and sustained contractions in the different muscle groups. These occur in an order, consistent with the cephalo-caudal direction of structural development in the nervous system. The changes of posture have never been observed, and at this stage the foetal limbs are not radiologically visible. If the functional development is in time with the segmental level of motor innervation the postural changes affect the foetal legs in the following order: hip flexion (L.2 and 3), adduction (L.3 and 4) and knee extension (L.3 and 4). Such movements produce breech malposition.

At the thirtieth week of gestation, when the foetal limbs are radiologically visible, Vartan (1945) observed the breech malposition in one out of every four foetuses. When the knees appeared partly flexed, the majority of foetuses eventually underwent spontaneous version. In those with fully extended knees the malposition persisted and was present at birth. Version occurred early in most multigravidae but was delayed in the primigravidae.

The development of the two breech malpositions is shown diagrammatically in Figure 20 . The important stage is the initiation of knee flexion or extension. The decisive factor is dorsiflexion of the foot (L.4 and 5) which, according to Weiss (1939), normally precedes knee flexion (S.1 and 2). When the dorsiflexed foot descends it is accommodated on the chest wall 
by lateral rotation of the limb. This is followed by knee flexion and folding of the breech malposition.

Delay in peripheral nerve development causes the dorsiflexor muscles to remain weak and thus allows the foot to be moulded into equinus. The adductor muscles then rotate the limb

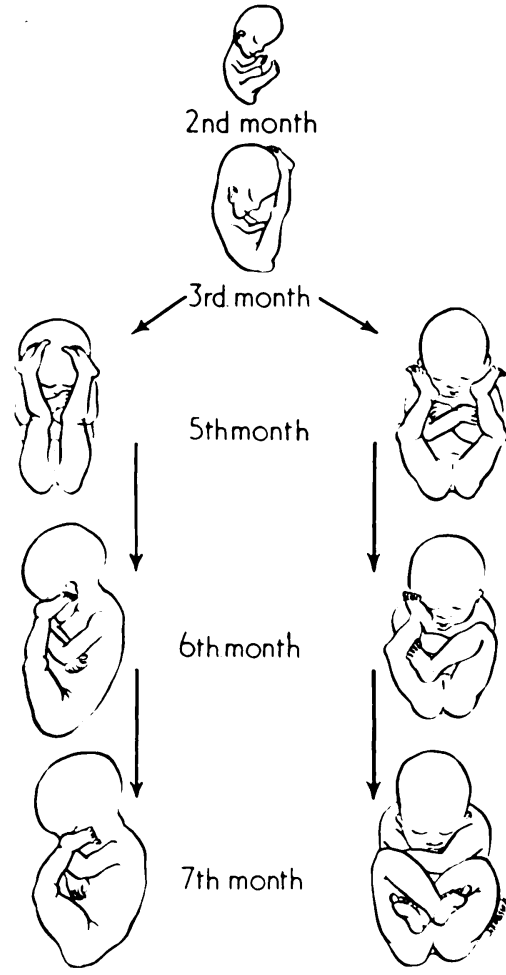

Fig. 20

The development of breech malposition in utero. The left side shows the persistent medial rotation breech posture. The right side shows the pre-version folding of the more common lateral rotation breech posture. medially and the quadriceps muscles hyperextend the knee. In most cases the delay is physiological, but it may be pathological in origin as in spina bifida and myelodysplasia, conditions which are frequently associated with persistent breech malposition and frank breech births.

The co-existence of the two factors in utero is evident; during the second trimester hormonal joint laxity develops and the breech malposition is assumed. The former persists, but the latter usually disappears in the early part of the third trimester.

Lateral rotation breech malposition and hormonal joint laxity have been shown to be the prime factors producing experimental, atraumatic dislocations in the hips of immature rabbits. The experimental mechanism resembles the pattern of sustained movements which bring about the folding of the human breech malposition, and it is maintained that this intra-uterine manoeuvre is the common mechanical factor producing congenital dislocation of the hip. The thesis is supported by the close anatomical similarity between experimental dislocations and neonatal specimens of congenital dislocations. Hormonal joint laxity is present in the majority of females with congenital dislocations, whereas familial joint laxity is found in the majority of affected males.

The lateral rotation breech malposition (Fig. 1) and the medial rotation posture (Fig. 2) produce respectively femoral retroversion associated with posterior acetabular dysplasia, and femoral anteversion with anterior dysplasia. In the newborn infant the former malposition tends to produce posterior dislocation of the hip and the latter to produce anterior subluxation. Extension increases the instability of the hip in each case and this explains the post-natal tendency for dislocation of the hip and the stabilising effect of abduction splinting. If the legs are held in Lorenz splints the femoral deformities are also corrected (Wilkinson 1962), thus reducing the risk of recurrent dislocation.

\section{SUMMARY}

1. Breech malposition and hormonal joint laxity produce atraumatic posterior dislocations in the hip joints of young rabbits.

2. Experimental studies were shown to cause the development of a limbus and other softtissue changes similar to those found in human congenital dislocations.

3. The development of femoral retroversion and anteversion in the presence of joint laxity is described.

4. The co-existence of breech malposition and hormonal joint laxity in utero, and their importance as prime factors in the etiology of congenital dislocation of the hip, are discussed. 
It gives me great pleasure to thank Mr H. J. Seddon and the Joint Clinical Research Committee of the Royal National Orthopaedic Hospital for the opportunity to perform this research in the Wellcome Research Laboratories, Institute of Orthopaedics, Stanmore. The experience and skill of $\mathrm{Mr}$ Joseph Cioch, Senior Animal Technician, greatly contributed to the success of the experiments. I am indebted to my colleague, Dr W. F. White, for his photography of my dissections. Photographs were also provided by the Photographic Department of the Royal National Orthopaedic Hospital and the illustrations are by Miss Jill Hassell, the Medical Artist, Westminster Hospital.

\section{REFERENCES}

ANDrén, L., and Borglin, N. E. (1961): Disturbed Urinary Excretion Pattern of Oestrogens in Newborns with Congenital Dislocation of the Hip. Acta Endocrinologica, 37, 423, 427.

ANDrén, L., and von Rosen, S. (1958): The Diagnosis of Dislocation of the Hip in Newborns. Acta Radiologica, 49, 89.

Appleton, A. B. (1934): Postural Deformities and Bone Growth. Lancet, i, 451.

ARkin, A. M., and KATZ, J. F. (1956): The Effects of Pressure on Epiphyseal Growth. Journal of Bone and Joint Surgery, 38-A, 1,056.

Browne, D. (1936): Congenital Deformities of Mechanical Origin. Proceedings of the Royal Society of Medicine (Section for the Study of Disease in Children), 29, 1,409.

Chapple, C. C., and Davidson, D. T. (1941): A Study of the Relationship between Fetal Position and Certain Congenital Deformities. Journal of Pediatrics, 18, 483.

Diczfalusy, E., Cassmer, O., Alonso, C., and Miquel, M. de (1961): Oestrogen Metabolism in the Human Foetus. Acta Endocrinologica, 37, 353.

FABER, A. (1937): Das Röntgenbild des Hüftgelunks beim Säugling. Verhandlungen der Deutschen Orthopädischen Gesellschaft, 32, 251.

Fairbank, H. A. T. (1930): Congenital Dislocation of the Hip: with Special Reference to the Anatomy. British Journal of Surgery, 17, 380.

FORBES, T. R. (1955): Apparent Secretion of Progesterone by Human and Goat Fetuses. Endocrinology, 56, 699.

HisAw, F. L. (1926): Experimental Relaxation of the Pubic Ligament of the Guinea Pig. Proceedings of the Society for Experimental Biology and Medicine, 23, 661.

Hisaw, F. L., Zarrow, M. X., Money, W. L., Talmage, R. V. N., and Abramowitz, A. A. (1944): Importance of the Female Reproductive Tract in the Formation of Relaxin. Endocrinology, 34, 122.

Jost, A. (1954): Hormonal Factors in the Development of the Fetus. Cold Spring Harbor Symposia on Quantitative Biology, 19, 167.

KeIth, Sir A. (1948): Human Embryology and Morphology. Sixth edition. London: Edward Arnold and Co. Le Damany, P. (1914): Congenital Luxation of the Hip. American Journal of Orthopedic Surgery, 11, 541.

Martin, J. M., and Schoenbach, U. (1959): Historical Aspects of Relaxin. Annals of the New York Academy of Sciences, 75, 923.

Ortolani, M. (1948): La lussazione congenita dell'anca. Bologna: Cappelli Editore.

Palmén, K. (1961): Preluxation of the Hip Joint. Acta Paediatrica, 50, Supplement 129.

Pinkerton, J. H. M. (1959): Oestrogen Production in the Immature Human Ovary. Journal of Obstetrics and Gynaecology of the British Empire, 66, 820.

Platt, Sir H. (1956): Congenital Dislocation of the Hip: The Role of Open Reduction. In Modern Trends in Orthopaedics (second series), p. 93. London: Butterworth \& Co. (Publishers) Ltd.

RECORD, R. G., and Edwards, J. H. (1958): Environmental Influences Related to the Aetiology of Congenital Dislocation of the Hip. British Journal of Preventive and Social Medicine, 12, 8.

TubBy, A. H. (1912): Deformities. Second edition. Vol. 1. London: Macmillan \& Co.

VARTAN, C. K. (1945): The Behaviour of the Foetus in Utero with Special Reference to the Incidence of Breech Presentation at Term. Journal of Obstetrics and Gynaecology of the British Empire, 52, 417.

Weiss, P. (1939): Principles of Development. New York: Henry Holt \& Company, Inc.

Wilkinson, J. A. (1962): Femoral Anteversion in the Rabbit. Journal of Bone and Joint Surgery, 44-B, 386.

Wilkinson, J., and CARTER, C. (1960): Congenital Dislocation of the Hip. Journal of Bone and Joint Surgery, 42-B, 669.

vol. 45 B, NO. 2, MAY 1963 